\title{
GASTRIC FUNCTION IN CAIMAN CROCODILUS (CROCODYLIA: REPTILIA)-I. RATE OF GASTRIC DIGESTION AND GASTRIC MOTILITY AS A FUNCTION OF TEMPERATURE
}

\author{
Carlos O. da C. Diefenbach* \\ Department of Zoology, The University of Michigan, Ann Arbor, \\ Michigan 48104, U.S.A.
}

(Received 20 March 1974)

\begin{abstract}
A cannulation method was devised that allows continuous safe gastric sampling and recording of intragastric pressure in Caiman crocodilus.

2. In $C$. crocodilus, fed 5 per cent of the body weight, complete gastric emptying takes an average of $99( \pm 10) \mathrm{hr}$ at $30^{\circ} \mathrm{C}$, to an average of $315( \pm 16) \mathrm{hr}$ at $15^{\circ} \mathrm{C}$.

3. Two types of gastric contractions were recorded in $C$. crocodilus, by means of intragastric pressure measurements, at 20,25 and $30^{\circ} \mathrm{C}$.

4. The two types of contractions were recorded regardless of the feeding state of the animals.

5. Their frequency and amplitude increase with temperature or upon feeding.
\end{abstract}

\section{INTRODUCTION}

Crocodilians are by far the largest and heaviest recent reptiles (Bellairs, 1969). They gulp their food in large pieces, including bones, with little mechanical breakdown. The main reduction in size and chemical degradation occurs at the level of the stomach, forcing the digestive enzymes and gastric acid to act at the surface of the food mass unless gastroliths aid breakup (Prosser \& Brown, 1960; Wilson, 1972).

The main physiological events in the stomach of vertebrate carnivores have generally been stated to be (1) secretion of highly concentrated hydrochloric acid, (2) secretion and activity of proteolytic enzymes and (3) rhythmic contractions (Code \& Carlson, 1968; Davenport, 1971). The hydrochloric acid, the concentration of which may reach 150 $170 \mathrm{mN}$ in some carnivores (Davson, 1970; Hunt \& Wan, 1967), provides an adequate ambient for the action of enzymes, particularly pepsins (Prosser \& Brown, 1960; Gordon et al., 1972). The acid also serves as a primary agent for the degradation of bones and other hard structures included in the diet, like calcareous exoskeletons and shells (Coulson \& Hernandez, 1964). A sterilizing effect through inhibition and/or destruction of putrefying bacteria is also attributed to the acid secretion (Smit, 1968). The pepsins present in the stomach initiate the lysis of protein molecules. They then yield smaller units (polypeptides) which are more easily degraded by enzymes secreted further along the digestive tract

* Present address: Department de Fisiologia, Farmacologia e Biofisica, Univ. Fed. do R. G. do Sul, Cx. Postal 592, Porto Alegre, RGS, Brazil. (trypsins and chemotrypsins) (Davson, 1970). The motility of the stomach assures faster contact of the food mass with the gastric secretions than by passive chemical diffusion. These contractions might enhance the grinding effects of hard objects found in the lumen of the stomach of some reptiles and birds (Friant, 1941; Smit, 1968).

Most works dealing with the gastro-intestinal tract of reptiles treat it on one level or another of morphology (gross morphology, histology and cytology). Research on the physiology of the digestion is very limited; it includes fewer than 10 per cent of the total number of published works. Most such studies proceeded under laboratory conditions and the animals were killed and their guts examined at intervals after ingestion. Besides being wasteful with species close to being endangered this approach lacks continuity. The present study reports on a method achieving continuous samples of gastric contents and movements and provides data on the feeding regime in the vicinity of the preferred body temperatures of Caiman crocodilus of various sizes (Diefenbach, 1975b).

\section{MATERIALS AND METHODS}

Sixteen specimens of Caiman crocodilus classified as small (30.5-38.5 cm total length, $N=8$ ), medium (56.0$65.0 \mathrm{~cm}$ total length, $N=6)$ and large $(84.0-96.0 \mathrm{~cm}$ total length, $N=2$ ) were used.

The gastric contents were sampled by aspiration and by chronic cannulation.

For chronic aspiration the fluids were pulled out directly through a $6 \mathrm{~mm}$ o.d. rubber tubing (lubricated with mineral oil) that was inserted into the stomach through the mouth at every collection time. 
Topographical criteria (dermal scutellation) were used to assure that the end of the tube was inside the fundus. The gastric contents were aspirated by an attached syringe and the tube removed after every sampling. This method was somewhat traumatic for some of the animals; consequently, the present experiments were proceeded by chronic cannulation which gave equivalent results.

For chronic cannulation a tube of polyethelene (No. 280 for the large animals, No. 180 for the small and medium) was implanted into the lumen of the stomach, and permanently connected to the outside through an incision in the floor of the pharynx, lateral to the basihyal cartilaginous plate. The pylorus of the crocodilians opens into the duodenum laterally and anteriorly from the fundus. The material of the catheter was sufficiently rigid to keep it in the blind sac of the fundus. Information about the location of the stomach in relation to the outside topography was obtained by dissection of animals of several size classes. With this information at hand, the polyethylene catheters were cut and bent into a suitable shape and length. The dissection of two animals which died accidentally from causes unrelated to the experiments confirmed that the tip of the catheter was inside the fundus of the stomach, specifically in the "blind sac" (Fig. 1). The animals cannulated in this manner ate readily, without apparent signs of being disturbed by the catheter. The outside end of the catheter was stoppered and strapped to the animal's neck with surgical adhesive tape which resists immersion in water. (Fig. 2).

Before collecting secretions $2 \mathrm{~cm}^{3}$ of air were first injected into the catheter. The gastric contents flowed spontaneously thereafter, and a gentle squeezing of the abdomen of the animals induced the flow of more fluids. The dead space of every cannula was measured prior to to insertion in the animal. At the beginning and at the end of each sampling procedure the dead space volume of fluids was blown back into the stomach and the tube capped. Hence the lumen of the catheter remained relatively clear of fluids between experiments.

Samples were collected from animals kept and fed at the following temperatures: $15^{\circ} \mathrm{C}\left( \pm 1.5^{\circ} \mathrm{C}\right)$-small animals only; $20^{\circ} \mathrm{C}\left( \pm 1.0^{\circ} \mathrm{C}\right)$-all size classes; $25^{\circ} \mathrm{C}$ $\left( \pm 1 \cdot 0^{\circ} \mathrm{C}\right)$-all size classes; $30^{\circ} \mathrm{C}\left( \pm 1.0^{\circ} \mathrm{C}\right)$-all size classes. All animals were sampled for $2-4 \mathrm{hr}$ prior to being fed, in what was considered a fasting condition (10-15 days without food).

The caimans were fed neonate (hairless, weight around $4 \mathrm{~g}$ ) and adult mice to an amount equal to 5 per cent of the body weight at each feeding. In one series of experiments the medium animals were fed $a d l i b$. The adult mice, skinned in order to avoid any abnormal accumulation of hair in the stomach, were fed only to the large caimans.

The $\mathrm{pH}$ of the gastric samples was measured within 2 min after collection and immediately afterwards the samples were cooled to $-1{ }^{\circ} \mathrm{C}$ and centrifuged at 4000 $\mathrm{rev} / \mathrm{min}$ for determination of solid residues. The results of the measurements of $\mathrm{pH}$ are reported in another publication (Diefenbach, 1975a).

Six animal, two small and four of medium size, were tested for gastric motility. The fundus of these animals was cannulated as previously described and a balloon of soft rubber from surgical gloves was formed over the end of the cannula. When inflated with air the balloons had a distended, but no stretched volume of $2 \mathrm{~cm}^{3}$ for the small animals and $4 \mathrm{~cm}^{3}$ for the medium ones. The cannulas were attached to a Statham pressure gauge, through a standard length of $1 \mathrm{~cm}$ dia. rubber tubing. The output of the pressure gauge was recorded on a Beckman Model $\mathbf{R}$ Dynograph in parallel with temperature. The animals were tested by two methods: (1) placed into a tube with water up to the level of the neck as described in Diefenbach (1973), and (2) unrestrained, placed in an aquarium, with enough water to cover their backs. The first method determines the effect of ventilation on the recordings of pressure. This was achieved by observing the animals through closed circuit television, and correlating the changes in the recordings of pressure with changes in the water line around the animal. Oscillations of a very light piece of aluminium foil or cotton, hanging in front of the nasal openings, helped to confirm when ventilation occurred. Each animal was tested once in the first arrangement, to determine the effects of its ventilation upon the intragastric recordings of pressure.

The unrestrained animals were fed while moving freely in the aquarium. For each animal the gastric motility was recorded during a sequence starting after a 3-week fast followed by feeding and continuing 5-10 days into the next fast. Records of motility were taken from animals kept at 20,25 and $30^{\circ} \mathrm{C}$. Several animals yielded more than one such record.

\section{RESULTS}

\section{Rate of gastric digestion and temperature}

The results of these experiments are summarized in Table 1. The length of time that the food remains in the stomach (from here on referred to as gastric residence time) ranges from 4 to 5 days, at a temperature of $30^{\circ} \mathrm{C}$, to more than 14 days at a temperature of $15^{\circ} \mathrm{C}$. The results at $15^{\circ} \mathrm{C}$ were limited to small animals. Medium and large animals could not be induced to eat spontaneously at this temperature. All animals ate at $20^{\circ} \mathrm{C}$. However, sometimes more than 2 weeks elapsed after their stomach was considered empty, before the large ones would again eat spontaneously. Thus, only a few experiments were carried out on large animals kept at $20^{\circ} \mathrm{C}$.

The two criteria used to define the termination of the gastric residence time were: (1) changes in color of the sample, and (2) decrease of residue left after centrifugation of the sample to less than 10 per cent of the collected volume. In animals known to be fasting the samples were clear (translucent) and of yellowish, sometimes green color. The samples taken during the gastric residence time were muddy and brown. When the samples taken after the animals had eaten were again translucent, of similar color and residue content as those of fasting animals, the gastric residence time was considered ended.

The gastric residence times were similar for all three sizes of animals when fed the standard diet and kept at similar temperatures. Four medium animals at $25^{\circ} \mathrm{C}$ fed ad lib, had higher mean residence times $(177 \pm 18 \mathrm{hr})$ than did the same animals, at the same temperature, when fed the standard diet $(139 \pm 17 \mathrm{hr})$

The amount of samples withdrawn from the animals during the measurements of gastric residence 

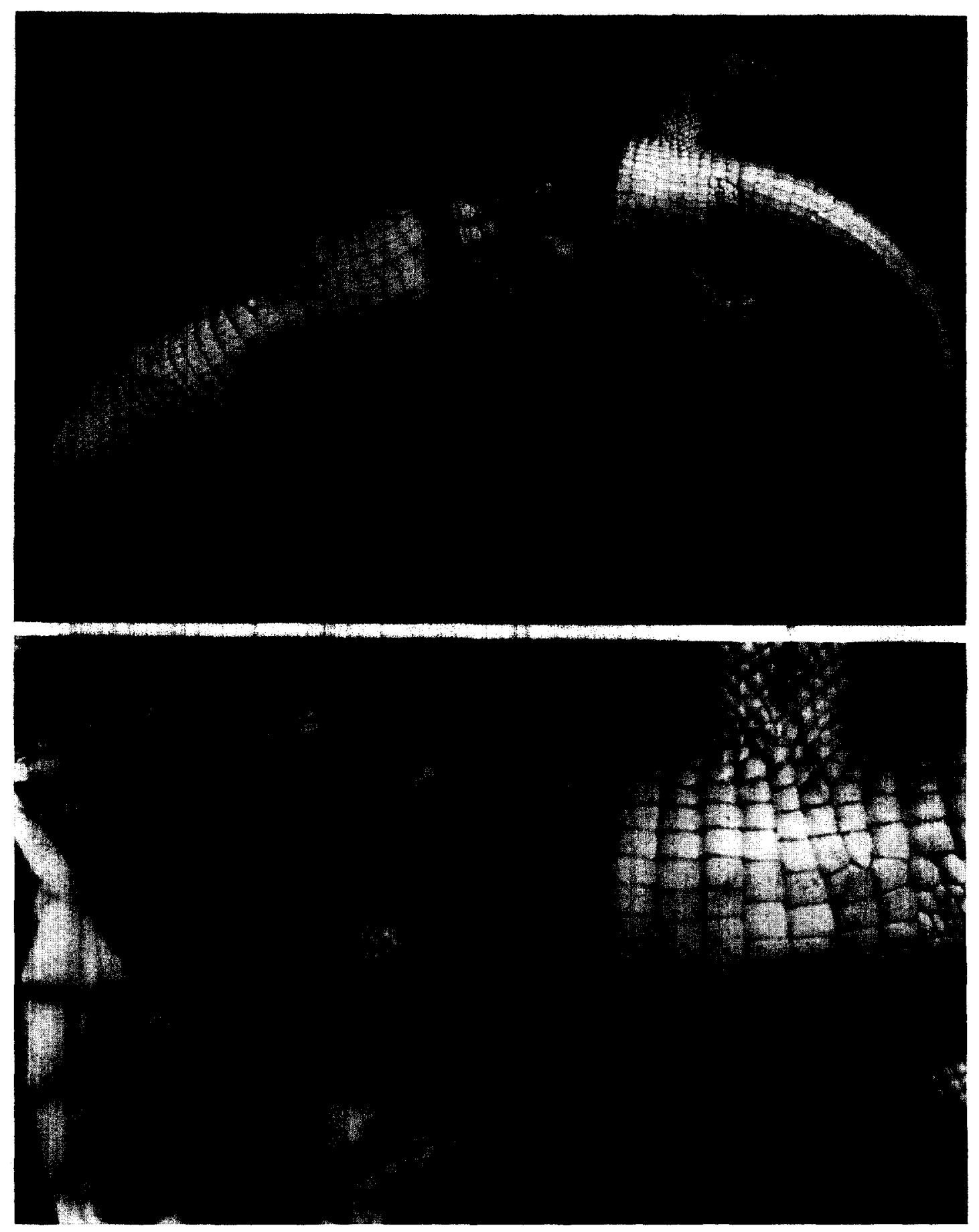

Fig. 1. Photograph of one of the "small" animals used in the experiments on gastric digestion, to show the location of the cannula inside the fundus. The cannula, in the close-up picture, is indicated by the arrow. 


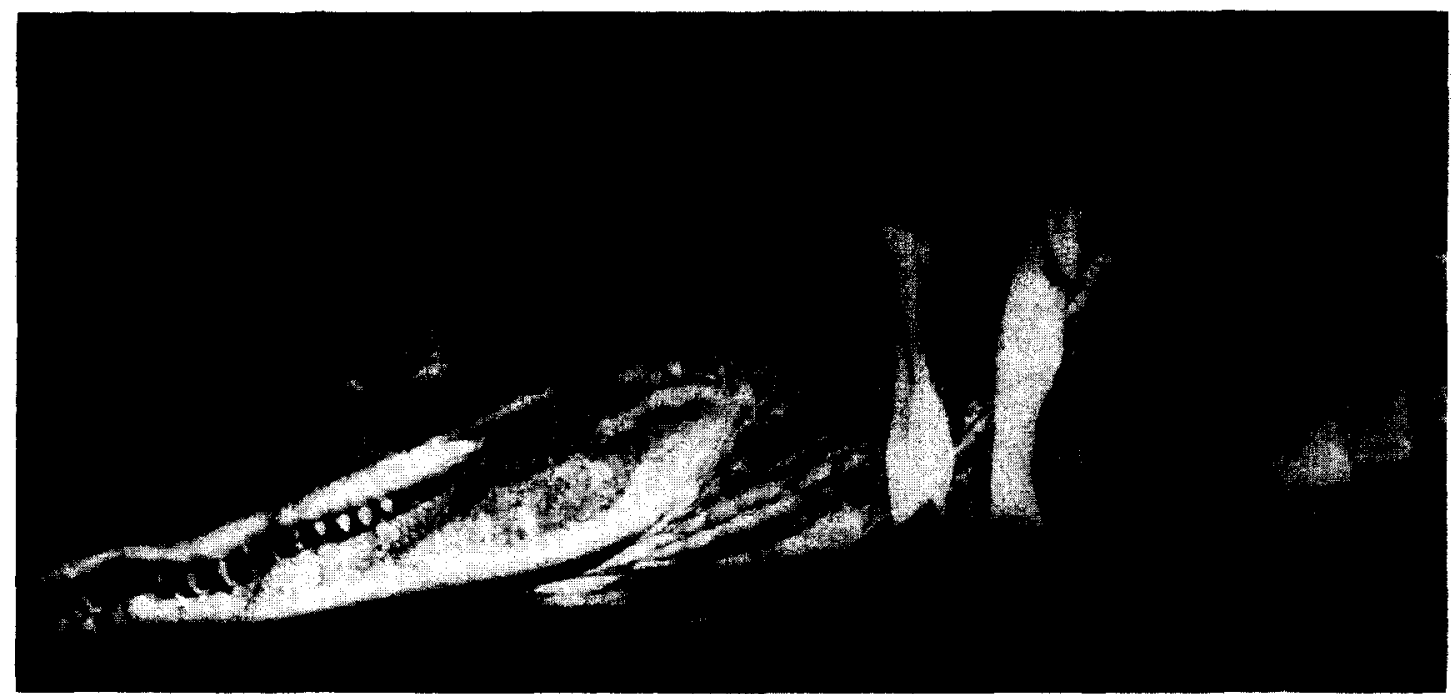

Fig. 2. Photograph of a "large" animal with a cannula chronically implanted in the stomach. Notice the cannula exiting at the floor of the pharynx. The bands of surgical tape around the neck keep the cannula in place. 


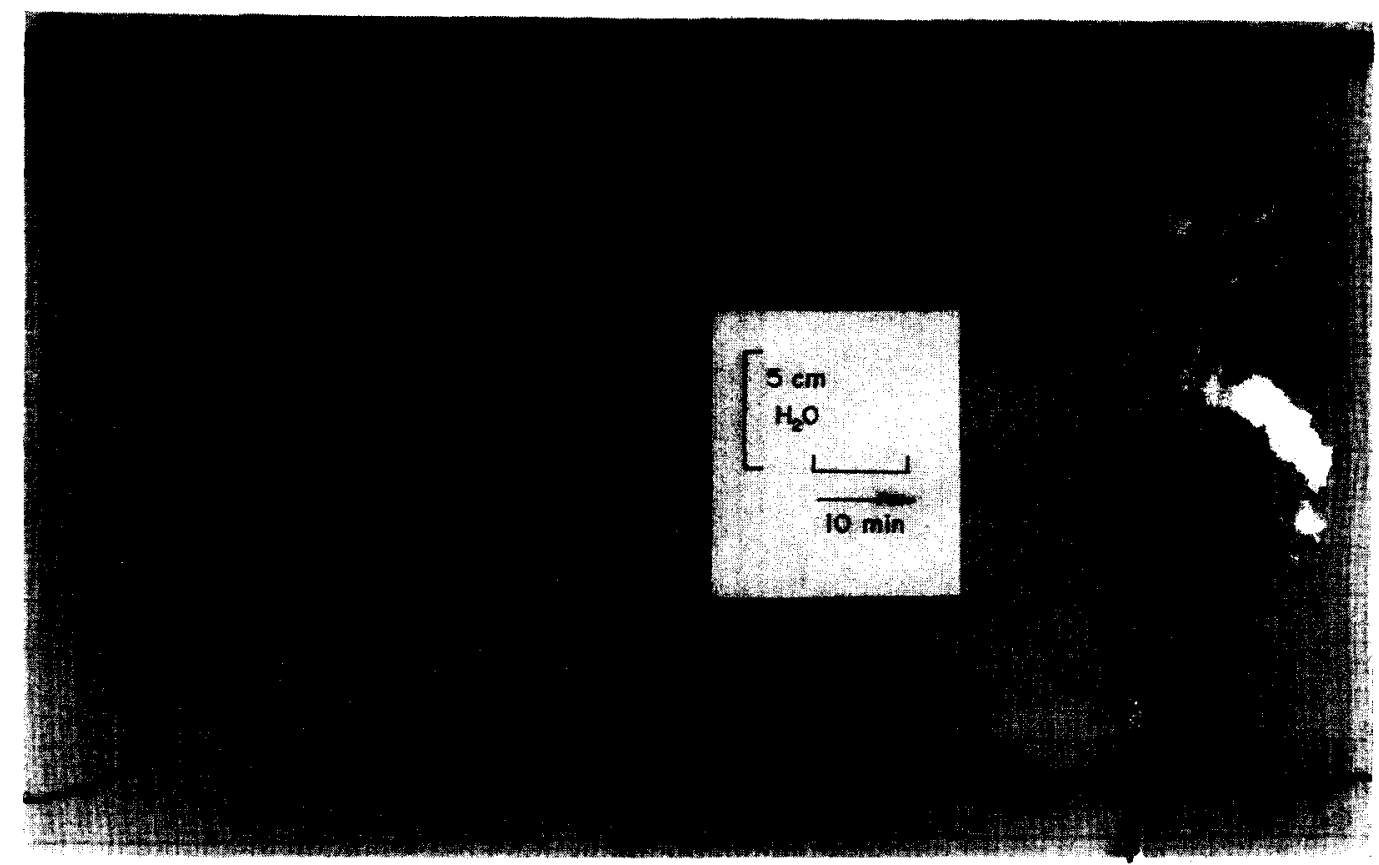

Fig. 4. Gastric motility in $C$. crocodilus. Contractions in a fasting animal, at $20^{\circ} \mathrm{C}$. At the right side is a complex wave; the three smaller waves at the left are simple. At the extreme left left is an expanded simple wave, with the time scale sixty times higher than that indicated (see second markings at the left of vertical dividing line). Read from left to right.

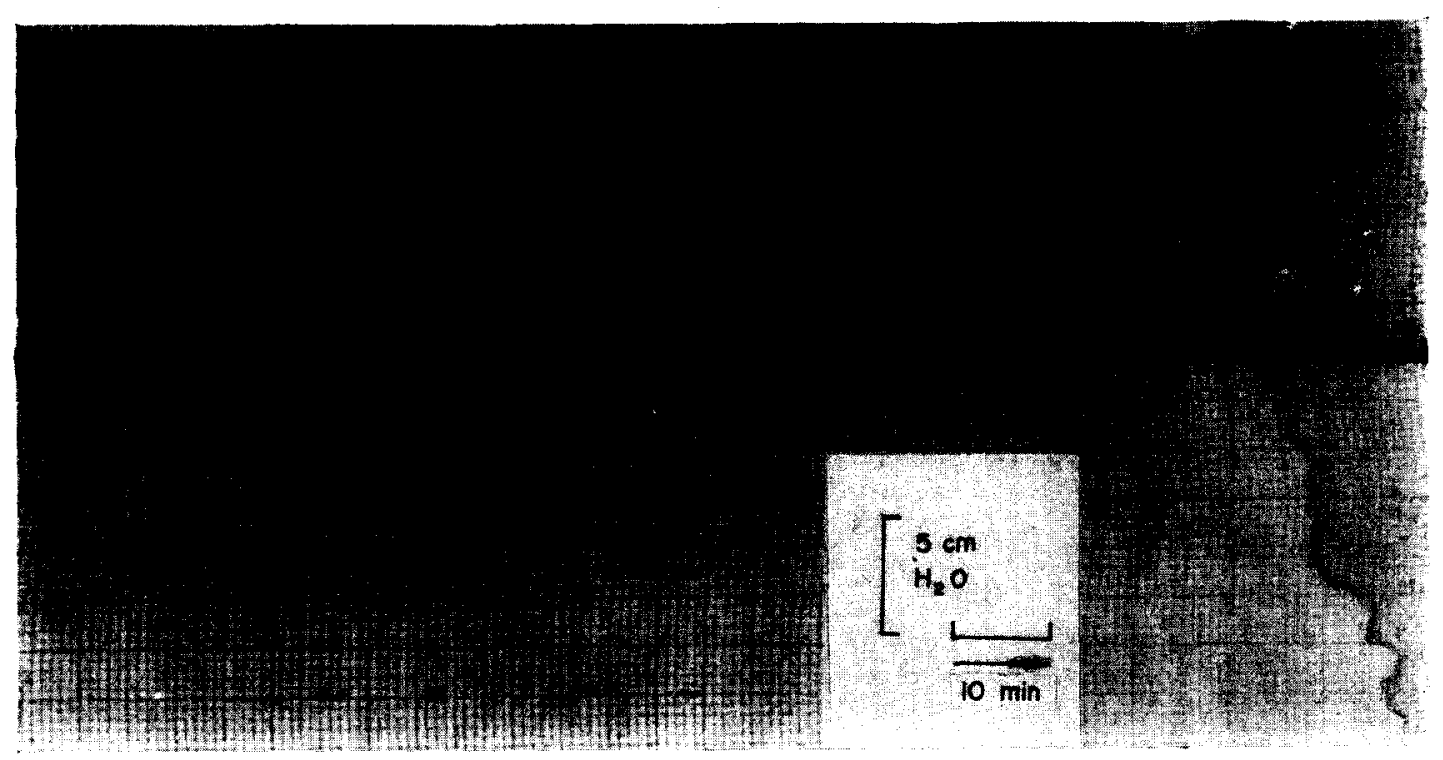

Fig. 5. Gastric motility in $C$. crocodilus. Contractions in an animal during fasting (12 days without food) and immediately after feeding, at $20^{\circ} \mathrm{C}$. The vertical arrow indicates the time when the animal ate five neonate mice. Read from left to right. 
Table 1. Gastric residence times of $C$. crocodilus fed 5 per cent of body weight*

\begin{tabular}{|c|c|c|c|c|c|c|}
\hline \multirow{2}{*}{$\begin{array}{c}\text { Temperature } \\
\left({ }^{\circ} \mathrm{C}\right)\end{array}$} & \multicolumn{2}{|c|}{ Small $(N=4)$} & \multicolumn{2}{|c|}{ Medium $(N=4)$} & \multicolumn{2}{|c|}{ Large $(N=2)$} \\
\hline & $\begin{array}{l}\mathrm{r}: \\
\dot{X}: \\
\mathrm{SD} \\
n:\end{array}$ & $\begin{array}{l}290-340 \mathrm{hr} \\
315 \mathrm{hr} \\
16 \mathrm{hr} \\
8\end{array}$ & & & & \\
\hline 20 & $\begin{array}{l}r: \\
\dot{X}: \\
\mathrm{SD}: \\
n:\end{array}$ & $\begin{array}{l}160-230 \mathrm{hr} \\
198 \mathrm{hr} \\
23 \mathrm{hr} \\
12\end{array}$ & $\begin{array}{l}r: \\
\dot{X}: \\
\text { SD: } \\
n:\end{array}$ & $\begin{array}{l}160-240 \mathrm{hr} \\
197 \mathrm{hr} \\
26 \mathrm{hr} \\
10\end{array}$ & $\begin{array}{l}r: \\
\dot{X}: \\
\text { SD: } \\
n:\end{array}$ & $\begin{array}{l}170-230 \mathrm{hr} \\
196 \mathrm{hr} \\
24 \mathrm{hr} \\
8\end{array}$ \\
\hline 25 & $\begin{array}{l}r: \\
\dot{X}: \\
\text { SD: } \\
n:\end{array}$ & $\begin{array}{l}115-170 \mathrm{hr} \\
139 \mathrm{hr} \\
17 \mathrm{hr} \\
12\end{array}$ & $\begin{array}{l}r: \\
\ddot{P}: \\
\text { SD: } \\
n:\end{array}$ & $\begin{array}{l}115-170 \mathrm{hr} \\
136 \mathrm{hr} \\
15 \mathrm{hr} \\
12\end{array}$ & $\begin{array}{l}r: \\
\dot{X}: \\
\text { SD: } \\
n:\end{array}$ & $\begin{array}{l}115-155 \mathrm{hr} \\
134 \mathrm{hr} \\
13 \mathrm{hr} \\
8\end{array}$ \\
\hline 30 & $\begin{array}{l}r: \\
\dot{P}: \\
\mathrm{SD} \\
n:\end{array}$ & $\begin{array}{l}90-126 \mathrm{hr} \\
106 \mathrm{hr} \\
11 \mathrm{hr} \\
12\end{array}$ & $\begin{array}{l}r: \\
\dot{X}: \\
\mathrm{SD}: \\
n:\end{array}$ & $\begin{array}{l}85-126 \mathrm{hr} \\
103 \mathrm{hr} \\
12 \mathrm{hr} \\
12\end{array}$ & $\begin{array}{l}r: \\
\not{X}: \\
\mathrm{SD}: \\
n:\end{array}$ & $\begin{array}{l}85-120 \mathrm{hr} \\
99 \mathrm{hr} \\
10 \mathrm{hr} \\
10\end{array}$ \\
\hline
\end{tabular}

* $N$, Number of animals used in the calculations.

$n$, Number of experiments with every group of animals used for calculations; $r$, range; $\not$, Mean; SD, Standard deviation.

times never exceeded $1.0 \mathrm{ml}$. When, by either sampling method, more than $1.0 \mathrm{ml}$ was obtained, the excess was immediately injected back into the stomach. This avoided the removal of excessive ions from the animal, and the induction of an excessive alkalotic state.

\section{Gastric motility}

(a) Types of gastric contractions. Two clearly distinguishable types of contractions were recorded from the stomach of $C$. crocodilus. The first is a simple wave and consists of a contraction of rather smooth shape (in the recording trace), lasting 10-25 sec. The average duration of ten randomly selected simple waves gives a mean duration of approximately $15 \mathrm{sec}$. The amplitude of these waves is quite variable, ranging from 2 to $3 \mathrm{~cm}$ (minimum resolution of the apparatus used) to to $25 \mathrm{~cm}$ of water. One example of these simple waves is shown in Fig. 3, redrawn from the records on a $1: 1$ scale.

The second, or complex wave, has a longer duration, lasting 35-170 sec (Fig. 3). The amplitude of these waves is generally $15-30 \mathrm{~cm}$ of water, at all those temperatures tested, and less variable than of the simple waves. At 25 and $30^{\circ} \mathrm{C}$ the intervals between simple waves tend to be rather regular (Figs. 8 and 9) but they occur more irregularly at $20^{\circ} \mathrm{C}$ (Figs. 4-6). At $30^{\circ} \mathrm{C}$ the intervals are shorter than at $25^{\circ} \mathrm{C}$.

The complex waves seem to occur randomly at all temperatures tested and they do not seem to have constant (or integral multiple of a constant) interval. Only their frequency increases with temperature.
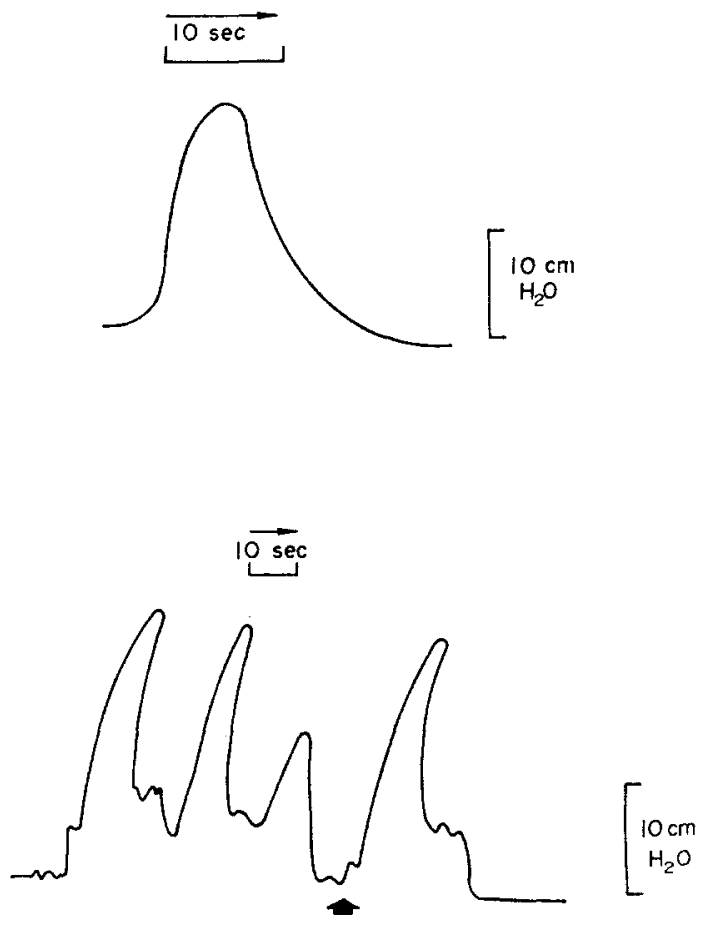

Fig. 3. Graphic illustration of a "simple wave" (top) and of a "complex wave" of gastric motility (bottom) in $C$. crocodilus. The arrow in the bottom of the complex wave indicates a recording of breathing, superimposed on the gastric motility's record. Both waves redrawn in $1: 1$ scale from the curvilinear chart records of the Beckman Model R Dynograph. Read from left to right. 
Also, it seems that at $30^{\circ} \mathrm{C}$ the complex waves, in spite of still being irregular, tend to occur at the beginning of trains of simple waves, as will be later described.

(b) Fasting at $20^{\circ} \mathrm{C}$. Fasting animals showed only an occasional simple wave, at very irregular intervals, sometimes lasting more than $40 \mathrm{~min}$. The amplitude of simple waves never exceeded $15 \mathrm{~cm}$ of water, and was generally below $10 \mathrm{~cm}$. At irregular intervals a complex wave could be noted. The amplitude of the complex waves was less variable, being as a rule between 15 and $25 \mathrm{~cm}$ of water (Fig. 4).

(c) Feeding at $20^{\circ} \mathrm{C}$. Feeding is immediately followed by a burst of activity, with simple and complex waves occuring at very short intervals (Fig. 5). After 3-5 hr more regular cycles start. The simple waves have long intervals, on the order of $150-300 \mathrm{sec}$ (Fig. 6) and they tend to occur in trains at intervals on the order of 60 or more minutes. The frequency of the simple waves at the middle of a train is approximately 3 waves $/ 10 \mathrm{~min}$ (Fig. 6). Occasionally a complex wave occurs between trains. The simple waves tend to have shorter intervals at the onset of each train (Fig. 6). This pattern of activity persists for 4-6 days, whereupon the activity gradually becomes more irregular; by the tenth day the activity again resembles that described for fasting animals. One should recall that by this time (approximately $240 \mathrm{hr}$ after feeding) the stomach is already quite empty of food.

(d) Fasting at $25^{\circ} \mathrm{C}$. The motility in fasting animals at $25^{\circ} \mathrm{C}$ is more regular than at $20^{\circ} \mathrm{C}$. The simple waves clearly occur in trains, with an interval between waves of 40 and $50 \mathrm{sec}$. Complex waves occur at random intervals. The complex waves sometimes occur between the simple waves in a train, otherwise between a train of simple waves. The trains of simple waves last between 50 and $90 \mathrm{~min}$ and are 15-40 min apart. The amplitude of the simple waves generally starts at $3 \mathrm{~cm}$ of water; toward the middle of each train this increases to approximately 15$20 \mathrm{~cm}$ of water. As each train approaches its end, the amplitude shows a fall to $10-15 \mathrm{~cm}$ of water (Fig. 7).

(e) After feeding at $25^{\circ} \mathrm{C}$. The rate of simple waves increases, and their amplitude is less variable, on the order of $10-15 \mathrm{~cm}$ of water (Fig. 8). Their frequency is approximately $1 / \mathrm{min}$ (Fig. 8). The complex waves still occur randomly and their amplitude sometimes reaches $30 \mathrm{~cm}$ of water. This pattern proceeds for 4-5 days, when the waves assume the characteristics described for fasting animals.

(f) At $30^{\circ} \mathrm{C}$. At this temperature the motility pattern seems to be the same for fasting and for recently fed animals. The simple waves occur in sharply defined trains. Each train has a duration of 20-35 min and the interval between trains is on the order of $8-15 \mathrm{~min}$. The amplitude of the simple waves is on the order of $8-12 \mathrm{~cm}$ of water, and they occur at intervals on the order of $15-25 \mathrm{sec}$. This gives a frequency of 2-4 simple waves per min (Fig.
9). The complex waves almost always occur at the beginning of the trains of simple waves (Fig. 9) and is of the order of $15-25 \mathrm{~cm}$ of water.

(g) Effects of breathing. The amplitude of waves due to ventilation was on the order of $3 \mathrm{~cm}$ or less, as a rule. Occasionally, when the animals were disturbed, the ventilatory movements became very deep and long lasting; they thus mimic gastric contractions. Nevertheless. such records caused by hyperventilation could be distinguished from gastric motility by noting hyperventilatory changes in the diameter of the animals. The animals hyperventilated when exceptionally excited. Care was taken to avoid disturbance, and cases of hyperventilation were not common. It must be said that by the time these experiments were carried out, the majority of the animals were used to the presence of the investigator. If handled carefully and gently, they did not show obvious signs of stress, of which the most conspicuous one would be hyperventilation ("hissing").

\section{DISCUSSION}

C. crocodilus will eat and digest its food through a range of more than $15^{\circ} \mathrm{C}$ (from 15 to $35^{\circ} \mathrm{C}$ ). There is a suggestion that small (and young) animals will still eat spontaneously at temperatures below $20^{\circ} \mathrm{C}$, when larger (and older) animals will no longer do so. Small animals apparently have a wider range of body temperature inside which they feed.

The gastric residence times of these caimans are much longer than those reported or inferred from reports for some other carnivorous reptiles. The lizards Uta stansburiana and Sceloporus graciosus had gastric residence times of less than $24 \mathrm{hr}$, when fed on insects (Knowlton, 1936); however, the thermal regime in which the animals were maintained is not stated. The snake Natrix natrix under more controlled temperature conditions had gastric residence times similar to those reported here. A frog eaten by $N$. natrix was observed with X-ray for a period of approximately 2-3 days (Skokzylas, 1970), though its liquified remnants may still have been present thereafter. Similar techniques used on other species of snakes (Blain \& Campbell, 1942) showed a gastric residence time of at least 5 days for a rat eaten by a boa constrictor.

Unfortunately, many authors did not specify the thermal regime in which the animals are maintained, which renders a meaningful comparison impossible. Similarly, the information for Chelydra serpentina and Emydoidea blandingii (Riddle, 1909) does not lend itself to useful comparisons with the present work since the method involved the use of Mett's tubes, the accuracy of which is doubtful (Hirschowitz, 1967) and which gives no indication of the real gastric residence time for a meal. The herbivore Ctenosaura pectinata had a complete passage time of 3-5 days, when fed a meal of sweet potatoes and 
maintained between $27^{\circ}$ and $37^{\circ} \mathrm{C}$ (Throckmorton, 1973).

The $\mathrm{pH}$ changes of gastric contents as well as the color and proportion of sediments in gastric samples after centrifugation suggest that the food stays in the stomach of $C$. crocodilus at least twice as long as earlier reported for Alligator mississippiensis (Coulson et al., 1950; Coulson \& Hernandez, 1964). These authors defined the end of gastric digestion by changes in the $\mathrm{pH}$ of blood, which is related to gastric secretion of hydrochloric acid ("alkaline tide"). When $C$. crocodilus were kept at temperatures lower than $20^{\circ} \mathrm{C}$, the gastric residence times extended for as long as 2 weeks. The results reported here are in good agreement with data on Caiman latirostris maintained near $30^{\circ} \mathrm{C}$ after a meal of fish (Coulson \& Hernandez, 1970), and killed at different intervals thereafter. However, these studies were directed mainly to changes in free amino acids of the whole carcass, and do not deal directly with the issue of gastric residence times. Other information regarding gastric residence time is not always clear or involves further problems. Some bony fishes (Cottus, Gadus) may take 5-6 days to completely digest a fish meal, while the same animals take only 3 days to digest a meal of small crustaceans (Gammarus) (Barrington, 1957). The gastric residence times for birds is generally less than $12 \mathrm{hr}$ (Sturkie, 1965).

Caution must be excercised before making conclusions about the emptying pattern of the stomach from data on the gastric residence time. The bulk of a liquid meal may have left the stomach long before the last remnants do so (Davenport, 1971). This applies for man (Hunt \& Spurrell, 1951) where the rate of emptying is apparently a function of the square root of the volume of the stomach (Hopkins, 1966).

The present work shows that at least 4 days at $30^{\circ} \mathrm{C}$ are necessary to complete gastric digestion of a meal comprising 5 per cent of the body weight in C. crocodilus. In their natural habitat, with circadian rhythms of light (and heat), the animals may not be able to maintain their preferred thermal levels for more than half a day. Therefore, wild animals should take longer to digest similar quantities of food. Other factors which can affect the gastric residence times are the amount of food ingested at one meal and the nature of the food itself. Larger sized food should take longer to digest, since the action of gastric secretions (acid and enzymes) is exerted only at the exposed surfaces.

Motion picture analysis during the present study documents that $C$. crocodilus swallows its prey by inertial feeding (Gans, 1969). Mechanical disruption caused during the process of arranging the prey for swallowing facilitates digestion, by increasing the exposed surface. The prey always undergo at least puncturing of the integumentary envelope; sometimes the body wall is torn and the viscera exposed, particularly in larger prey, which undergoes longer mastication prior to deglutition. The rate of digestion may also be affected by the water content and protective coatings such as hair, scales or chitin. Hair may retard the initial stages of gastric digestion by snakes; it slows down diffusion of the secretions (Root, 1961). The diet of small and young crocodilians in the wild includes such items as insects, small crustaceans, mollusks, small amphibians and fishes (Kellog, 1929; Welman \& Worthington, 1943; Corbet, 1959 a, b; Medem, 1960; Cott, 1961 ; Pooley, 1962; Neill, 1971). The proportion of fishes increases as the animals attain a larger size; occasional mammals and birds are also included (Corbett, 1959b; Cott, 1961). The present study suggests that crocodilians readily eat while still digesting an earlier meal, particularly if the amount of the previous meal was not ad lib.

The present study shows that gastric motility is drastically reduced at $20^{\circ} \mathrm{C}$; by extrapolation one can assume even less motility at $15^{\circ} \mathrm{C}$. Simultaneously, the hydrochloric acid is less concentrated (pH not below 2.0) and proteolytic activity reduced (Diefenbach, 1975). The bolus will be less "stirred", since the motility of the stomach certainly causes it to be thoroughly washed by secretion (Code \& Carlson, 1968). Motility may also abrade the bolus against various types of gastroliths in the stomach (Bakker, 1971). There is still doubt whether crocodilians ingest hard objects purposely or accidentally. The feeding habit of crocodilians may lead to accidental ingestion of gravel or other objects from the bottom of the water (Brazaitis, 1969; personal observation). There is also the possibility that gravel or rocks may have been in the stomach of the prey (Neill, 1971). Whether ingested accidentally or not, gastroliths probably enhance mechanical breakdown in the stomach.

The pressure transducers unavoidably picked up ventilatory pressure changes. The mechanics of breathing in crocodilians apparantly involves the musculus diaphragmaticus, which pulls the liver toward the pelvis to induce inspiration (Gans, 1970; Naifeh et al., 1970). Ventilation thus involves visceral shifts and compaction, including the stomach. However, the records due to breathing could be clearly distinguished from gastric contractions.

Fasting $C$. crocodilus has a constant level of gastric motility at 30 and $25^{\circ} \mathrm{C}$. The motility at $20^{\circ} \mathrm{C}$ is markedly lowered and irregular. The little activity at $20^{\circ} \mathrm{C}$ with an empty stomach consists mostly of complex waves. C. serpentina shows a similar pattern of gastric motility when fasting (Patterson, 1916, 1933); the waves have long duration $(120-150 \mathrm{sec})$, but a smoother shape than the complex wave of Caiman. Patterson described them as "tetanic-like" contractions. The contractions in Chelydra when in short fast (less than 1 week) are similar to the simple waves of Caiman. Gastric motility determined by telemetry capsules during the feeding 
process has been described in the lizards Varanus flavescens and C. pectinata (Mackay, 1968). The recorded contractions are similar to the simple waves of Caiman, varying in frequency and amplitude depending on body temperature and state of feeding. There was also a suggestion of circadian rhythm of of activity in these species.

The simple wave of Caiman described in the present work can be compared to the Type I contraction of the stomach of mammals (see Code \& Carlson, 1968). These are also of a rather smooth shape and similar duration (on the order of $15 \mathrm{sec}$ ). The complex wave of Caiman resembles the Type II contraction of mammals which also forms a smooth curve. The complex wave of Caiman does not seem to be rhythmic, which the Type II contractions occur at $22 \mathrm{sec}$, or multiple therefore, in man (Code \& Carlson, 1968). The complex wave of Caiman is not restricted to the periods of gastric digestion. As fasting proceeds, the Type I contraction of mammals gradually assumes the shape and duration of Type II, while the simple and complex waves always could be distinguished in Caiman. The frequency of the simple waves is clearly a direct function of temperature. At $30^{\circ} \mathrm{C}$ the simple waves reach frequencies of 2-3 per min. similar to the Type I waves of mammals. In mammals there occurs a more sublte contraction, the Type III, which escapes ordinary balloon recordings, because of the limited area of the stomach involved at any moment (Code \& Carlson, 1968). The Type I and II waves superimpose on this contraction, which is of a low amplitude increase in tonus. Presently there is no information of these contractions in C. crocodilus.

The fundic contractions here reported confirm anatomical considerations of the role during digestion of this part of the crocodilian stomach. The physiological role of the two types of contractions awaits further research, perhaps electrical recordings of the active stomach. The complex wave may be the result of fusion of two or more simple waves (H. W. Davenport, personal communication). The fundus has a thicker and more complex smooth muscle coats than do the cardiac and pyloric portions (Reese, 1913; Staley, 1925). The fundus has been compared to the gizzard of birds (Oppel, 1896; Biedermann, 1911; Pernkopf \& Lehner, 1937; von Wettstein, 1954), which is the section of the avian stomach responsible for mechanical disruption of the food. The fundus of crocodilians differs from the gizzard of birds in that it is also a storage vat (function of the crop in grain and fruit eating birds), and the site of secretions and chemical degradation. It should be remarked also that the avian gizzard is generally less thick in muscle in carnivorous species (Farner, 1960); thick muscle gizzards, with grit and gastroliths, are characteristic of granivorous species.

Acknowledgements-This investigation was part of the requirements of the State University of New York at
Buffalo, for the degree of Doctor of Philosophy. I thank Dr. Carl Gans, major advisor of this project, for his support and for providing the material facilities for carrying out the research and Dr. H. W. Davenport for valuable suggestions and criticisms. Mrs Sharon Ireland and $\mathrm{Mr}$ Alex Tompa for technical help and criticisms. Mr. L. Martonyi helped with the illustrations. This project was supported by the National Science Foundation (GB$31088 \mathrm{X}$ to $\mathrm{C}$. Gans) and by the Society of the Sigma Xi (Grant-in-aid of research).

\section{REFERENCES}

BAKKER R. T. (1971) Ecology of the brontosaurs. Nature, Lond. 229, 172-174.

BARRINGTON E. J. W. (1957) The alimentary canal and digestion. In The Physiology of Fishes (Edited by Brown M. E.) Vol. 1, Chapter 3. Academic Press, New York.

Bellairs A. (1969) The Life of Reptiles, Vol. 1. Weidenfeld \& Nicolson, London.

BieDERMANN W. (1911) Der Magensaft der Vögel, Reptilien und Amphibien-XII. Die Ernährung der höheren Wirbeltiere. In Handbuch der Vergleichenden Physiologie (Edited by WINTERSTEIN H.) Vol. 1, sec. 2. Fischer, Jena.

Blain A. W. \& Campbell K. N. (1942) A study of digestive phenomena in snakes, with the aid of the Roentgen ray. Am J. Roentgen 48, 229-239.

Brazartis P. J. (1969) The occurrence and ingestion of gastrolyths in two captive crocodilians. Herpetologica 25, 63-64.

CODE C. F. \& Carlson H. C. (1968) Motor activity of the stomach. In Handbook of Physiology sec. 6, vol. 4, chap. 93. Am. Physiol. Soc, Washington. D.C.

Corbet P. S. (1959a) Notes on the insect food of the Nile crocodile in Uganda. Proc. R. Ent. Soc. Lond. 34A, 17-22.

Corbet P. S. (1959b) The food of a sample of crocodiles Crocodylus niloticus L.) from Lake Victoria. Proc. Zool. Soc. Lond. 133, 561-572.

CoTt H. B. (1961) Scientific results of an inquiry into the ecology and economic status of the Nile crocodile (Crocodylus niloticus) in Uganda and Northern Rhodesia. Trans. Zool. Soc. Lond. 29, 211-337.

Coulson R. A. \& Hernandez T. (1964) Biochemistry of the Alligator. Louisiana State University Press, Baton Rouge.

Coulson R. A. \& Hernandez T. (1970) Protein digestion and amino-acid absorption in the cayman. J. Nutr. $100,810-826$.

Coulson R. A., Hernandez T. \& Dessauer H. (1950) Alkaline tide in the alligator. Proc. Soc. exp. Biol. Med. 74, 866-869.

DAVENPORT H. W. (1971) Physiology of the Digestive Tract, 3rd Ed. Year Book Medical Publishers, Chicago. Davson H. (1970) A Textbook of General Physiology, 4th Edn., Vol. 1. Williams \& Wilkins, Baltimore.

DiefenbaCh C. O. DA C. (1973) Integumentary permeability to water in Caiman crocodilus and Crocodylus niloticus (Crocodilia: Reptilia). Physiol. Zoöl. 46, 72-78.

DiefenbaCH C. O. DA C. (1975a) Gastric function in Caiman crocodilus (Crocodilia: Reptilia)-II. Effects of temperature on $\mathrm{pH}$ and proteolysis. Comp. Biochem. Physiol. 51A, 267-274. 
Diefenbach C. O. DA C. (1975b) Thermal preferences and thermoregulation in Caiman crocodilus. Copeia, 1975 (3).

FARNeR D. S. (1960) Digestion and the digestive system. In Biology and Comparative Physiology of Birds (Edited by Marshall A. J.), Vol. 1, chap. 11. Academic Press, New York.

FrianT M. (1941) La trituration des aliments par l'estomac chez les crocodiles. Bull. Mus. Nat. Paris 13, 405-407.

Gans C. (1969) Comments on inertial feeding. Copeia 1969, 855-857.

GANS C. (1970) Respiration in the early tetrapods - the frog is a red herring. Evolution 24, 740-751.

Gordon M. S., Bartholomew G. A., Grinnel A. D., JoRgensen C. B. \& White F. N. (1972) Animal Physiology: Principles and Adaptations. Macmillan, New York.

HiRschowitz B. I. (1967) Secretion of pepsinogen. In Handbook of Physiology, Sec. 6, Vol. 2, Chap. 50. Am. Physiol. Soc. Washington, D.C.

HopkINS A. (1966) The pattern of gastric emptying: a new view of old results. J. Physiol., Lond. 182, 144-149.

Hunt J. N. \& SpurRell W. R. (1951) The pattern of emptying of the human stomach. J. Physiol., Lond. 113, 157-168.

HUNT J. N. \& WAN B. (1967) Electrlytes of mammalian gastric juice. In Handbook of Physiology, Sec. 6, Vol. 2, Chap. 44. Am. Physiol. Soc., Washington, D.C.

KeLLOG R. (1929) The habits and economic importance of the alligators. U.S. Dept. Agric. Tech. Bull. 147, 1-36.

KNOwLtoN G. F. (1936) Lizard digestion studies. Herpetologica 1, 9-10.

MACKAY R. S. (1968) Observations on peristaltic activity versus temperature and circadian rhythms in undisturbed Varanus flavescens and Ctenosaura pectinata. Copeia 1968, 252-259.

MEDEM F. (1960) Dados Zoogeograficos y ecologicos sobre los Crocodylia y Testudinata de los rios Amazonas Putomayo y Caquita. Caldasia (Bogotá) 8, 341-351.

Naifeh K. H., Huggins S. E., Hoff H. E., Hugg T. W. \& Norton R. E. (1970) Respiratory patterns in crocodilian reptiles. Resp. Physiol. 9, 31-42.

NeILL W. T. (1971) The Last of the Ruling Reptiles. Columbia University Press, New York.

OPPEl A. (1896) Der Magen. In Lehrbuch der Vergleichenden Mikroskopischen Anatomie der Wirbeltiere, Vol. 1. Fischer, Jena.

Patterson T. L. (1916) Comparative studies in the physiology of gastric hunger contractions in the Amphibia and the Reptilia. Am. J. Physiol. 40, 140 141.
PATTERSON T. L. (1933) Comparative physiology of gastric hunger mechanism. Ann. N.Y. Acad. Sci. 34, 55-272.

Pernkopf E. \& Lehner J. (1937) Vergleichende Beschreibungen des Vorderdarms bei den einzelnen Klassen der Cranioten. In Handbuch der Vergleichenden Anatomie der Wirtbeliere (Edited by Kallius E., BoLK L., Goppert E. \& Lubosch W.), Vol. 3, Chap. 3. Urban und Schwarzenberg, Berlin.

PoOley A. C. (1962) The Nile crocodile, Crocodylus niloticus. The Lammergeyer (Natal) 2, 1-55.

Prosser C. L. \& Brown F. A., JR. (1960) Comparative Animal Physiology. Saunders, Philadelphia.

REESE A. M. (1913) The histology of the enteron of the Florida alligator. Anat. Rec. 7, 105-129.

RiDDle O. (1909) The rate of digestion in cold-blooded vertebrates-the influence of seasons and temperature. Am. J. Physiol. 24, 447-458.

RooT H. D. (1961) Gastric degestion with hypothermia: observations and applications. Ph.D. thesis, University of Minnesota. Abstract in Diss. Abstr. 22, 1954.

SkoKzYLAS R. (1970) Influence of temperature on gastric digestion in the grass snake, Natrix natrix L. Comp. Biochem. Physiol. 33, 793-804.

SMIT H. (1968) Gastric secretion in the lower vertebrates and birds. In Handbook of Physiology, Sect. 6, Vol. 5, Chapt. 135. Am. Physiol. Soc., Washington. D.C.

Staley F. H. (1925) A study of the gastric glands of Alligator mississippiensis. J. Morphol. 40, 169-189.

Sturkie P. D. (1965) Avian Physiology, 2nd Edn., Chapt. 11. Cornell University Press, Ithaca.

Throckmorton G. (1973) Digestive efficiency in the herbivorous lizard Ctenosaura pectinata. Copeia 1973, $431-435$.

Welman J. B. \& Worthington E. B. (1943) The food of the crocodile (Crocodilus niloticus L.). Proc. Zool. Soc. Lond. 113, 108-112.

von Wettstern O (1954) Crocodilia. In Handbuch der Zoologie (Edited by HelmcKe J. \& Von Lengerken H.), Vol. 7, Part 1, Chapt. 4, pp. 321-424. de Gruyter, Berlin.

Wilson J. A. (1972) Principles of Animal Physiology. Macmillan, New York.

Key Word Index-Caiman crocodilus; gastric digestion; temperature. 